\title{
Epidemiology and biology of physical activity and cancer recurrence
}

\author{
Christine M. Friedenreich ${ }^{1,2,3} \cdot$ Eileen Shaw $^{1} \cdot$ Heather K. Neilson ${ }^{1}$. \\ Darren R. Brenner ${ }^{1,2,3}$
}

Received: 6 April 2017 /Revised: 24 May 2017 / Accepted: 2 June 2017 /Published online: 15 June 2017

(C) The Author(s) 2017. This article is an open access publication

\begin{abstract}
Physical activity is emerging from epidemiologic research as a lifestyle factor that may improve survival from colorectal, breast, and prostate cancers. However, there is considerably less evidence relating physical activity to cancer recurrence and the biologic mechanisms underlying this association remain unclear. Cancer patients are surviving longer than ever before, and fear of cancer recurrence is an important concern. Herein, we provide an overview of the current epidemiologic evidence relating physical activity to cancer recurrence. We review the biologic mechanisms most commonly researched in the context of physical activity and cancer outcomes, and, using the example of colorectal cancer, we explore hypothesized mechanisms through which physical activity might intervene in the colorectal recurrence pathway. Our review highlights the importance of considering prediagnosis and post-diagnosis activity, as well as cancer stage and timing of recurrence, in epidemiologic studies. In addition, more epidemiologic research is needed with cancer recurrence as a consistently defined outcome studied separately from survival. Future mechanistic research using randomized controlled trials, specifically those demonstrating the exercise responsiveness of hypothesized mechanisms in early stages of carcinogenesis, are needed to inform recommendations about
\end{abstract}

Christine M. Friedenreich

christine.friedenreich@albertahealthservices.ca

1 Department of Cancer Epidemiology and Prevention Research, CancerControl Alberta, Alberta Health Services, $22102^{\text {nd }}$ St SW, Calgary, AB T2S 3C3, Canada

2 Department of Oncology, Cumming School of Medicine, University of Calgary, Calgary, AB, Canada

3 Department of Community Health Sciences, Cumming School of Medicine, University of Calgary, Calgary, AB, Canada when to exercise and to anticipate additive or synergistic effects with other preventive behaviors or treatments.

Keywords Physical activity $\cdot$ Exercise $\cdot$ Recurrence $\cdot$ Biomechanisms $\cdot$ Cancer

\section{Introduction}

Over the past two decades, it has become clear that physical activity is associated with reduced cancer incidence. A recent pooled analysis of epidemiologic studies showed that high levels of leisure-time physical activity are associated with statistically significantly lower risks of 10 different cancers, even after adjusting for body mass index (BMI) [1]. Achieving physical activity recommendations of the World Health Organization has been associated with a 7\% decrease in overall cancer risk, with the strongest associations observed for colorectal cancer and female breast cancer [2]. Considerably fewer epidemiologic studies have investigated the role of physical activity in relation to cancer outcomes, and the majority examined mortality (overall and/or cancer-specific) as an end point, without analyzing recurrence [3]. Of 33 reviews we identified in the past decade that investigated physical activity and cancer survivorship, only eight reviewed recurrences as a distinct endpoint [4-11].

Cancer patients are surviving longer than ever before, and fear of cancer recurrence is an important concern among cancer survivors [12]. In the USA, an estimated $40 \%$ of patients treated for local and locally advanced colorectal cancer experience cancer recurrence [13] and, for breast cancer, recurrences affect $11-20 \%$ of patients depending on tumor characteristics, stage of cancer, and treatment [14]. In this review, we provide an overview of the understudied association between physical activity and cancer recurrence. We review and 
discuss hypothesized pathways and mechanisms that might explain epidemiologic findings, using the example of colorectal cancer. We also highlight gaps in knowledge and future directions for this area of research.

\section{Epidemiologic evidence}

While there is strong and consistent observational evidence that increased physical activity is associated with increased overall survival in cancer survivors (mainly breast and colorectal [15]), as well as an inverse dose-response relationship with cancer-specific mortality [3], the evidence for physical activity in cancer recurrence is more limited (Table 1). Recurrence studies have been observational, mostly restricted to breast, colorectal, and prostate cancer survivor populations, and have found mixed results. There are several issues surrounding research on cancer recurrence that need to be recognized when examining the epidemiologic evidence. Cancer recurrence is difficult to study because most cancer registries do not routinely collect recurrence data [30]. Information on recurrence is generally only collected in clinical trials and is acquired through laborious chart reviews. In contrast, studies on cancer-specific and overall mortality are easier to conduct since these outcomes are readily accessible through tumor and vital registries and death certificates. Furthermore, varying definitions for cancer recurrence have been used which hinders comparisons between studies and may introduce error in the outcome assessments. For example, some definitions of recurrence outcomes include cancer-specific deaths or progressions (Table 1). Slow-developing recurrences are also difficult to assess because of the long follow-up required; observational studies might terminate active follow-up before a cancer recurrence is detected. In addition, studies may be underpowered to assess recurrence associations if the primary outcome (on which the sample size was based) is survival. Moreover, associations between recurrences and physical activity may be confounded by cancer symptoms or treatment, disease progression, and BMI.

To our knowledge, seven observational studies have investigated the effect of pre- or post-diagnosis physical activity and breast cancer events, defined as recurrence, progression, new primary breast cancers, or breast cancer-specific deaths [18-24]. A meta-analysis by Lahart et al. (2015) [10] provided pooled estimates for five of these studies that were protective (HR $=0.72,95 \%$ CI $0.56-0.91$ for pre-diagnosis physical activity $[18,19]$ and $\mathrm{HR}=0.79,95 \%$ CI $0.63-0.98$ for postdiagnosis physical activity $[21,23,24])$, although most individual studies had non-statistically significant protective effects for cancer recurrence. Similarly, two observational studies of colorectal cancer found that increased pre- or postdiagnosis physical activity was not statistically significantly associated with recurrence-free survival, although results suggested a protective trend [26, 27]. For prostate cancer, two studies were conducted and no associations were observed between pre- and post-diagnosis physical activity with increased recurrence or progression of prostate cancer [28, 29]. There are currently several additional cohort studies in progress; two focus on colorectal cancer recurrence [31, 32] and two on breast cancer recurrence [33, 34]. These studies will collect repeated measures of physical activity over the course of follow-up and examine overall survival, diseasefree survival, and/or recurrence as primary end points.

In addition to observational evidence, randomized controlled trials (RCTs) of exercise with recurrence outcomes are necessary for ruling out reverse causality, residual confounding, and evaluating the predictive nature of proposed biomarkers. There is emerging RCT evidence on the effect of post-diagnosis physical activity on cancer recurrence. To date, only the Supervised Trial of Aerobic versus Resistance Training (START) in breast cancer patients has published results, suggesting a protective exercise effect in patients diagnosed as human epidermal growth factor receptor 2 (HER2)positive and patients who completed $>85 \%$ of the average relative dose intensity of their originally planned chemotherapy regimen. However, the recurrence analysis from START was secondary and exploratory in nature and subgroups were based on small sample sizes [25]. Another trial in colon cancer patients that is ongoing is the Colon Health and Life-Long Exercise Change (CHALLENGE) Trial, designed specifically to evaluate the effect of post-diagnosis exercise on disease-free survival as a primary outcome [35]. There are currently a number of additional RCTs in cancer survivors investigating the effect of lifestyle (including physical activity) interventions on recurrence- or disease-free survival. One RCT in breast cancer patients involves an exercise plus diet for weight loss intervention [36], and three additional RCTs are ongoing that will test the relative impact of lifestyle interventions (generally diet, exercise, and vitamin D) [37-40] on breast cancer recurrence. In addition, there are several other registered trials currently ongoing that involve physical activity and cancer recurrence in breast (clincialtrials.gov identifiers: NCT02035631, NCT02786875, NCT03091842, NCT02750826, NCT02161900, NCT02240836), prostate (NCT02252484), ovarian (NCT02529150), endometrial (NCT03095664), and other cancer survivors (NCT02473003, NCT01693172). Results of these RCTs will provide further evidence of a causal association between physical activity (combined with other lifestyle changes) and cancer recurrence.

\section{Mechanisms}

The mechanisms whereby physical activity could lower recurrence risk in breast, colorectal, and prostate cancer patients are not well understood, although evidence has grown over the 


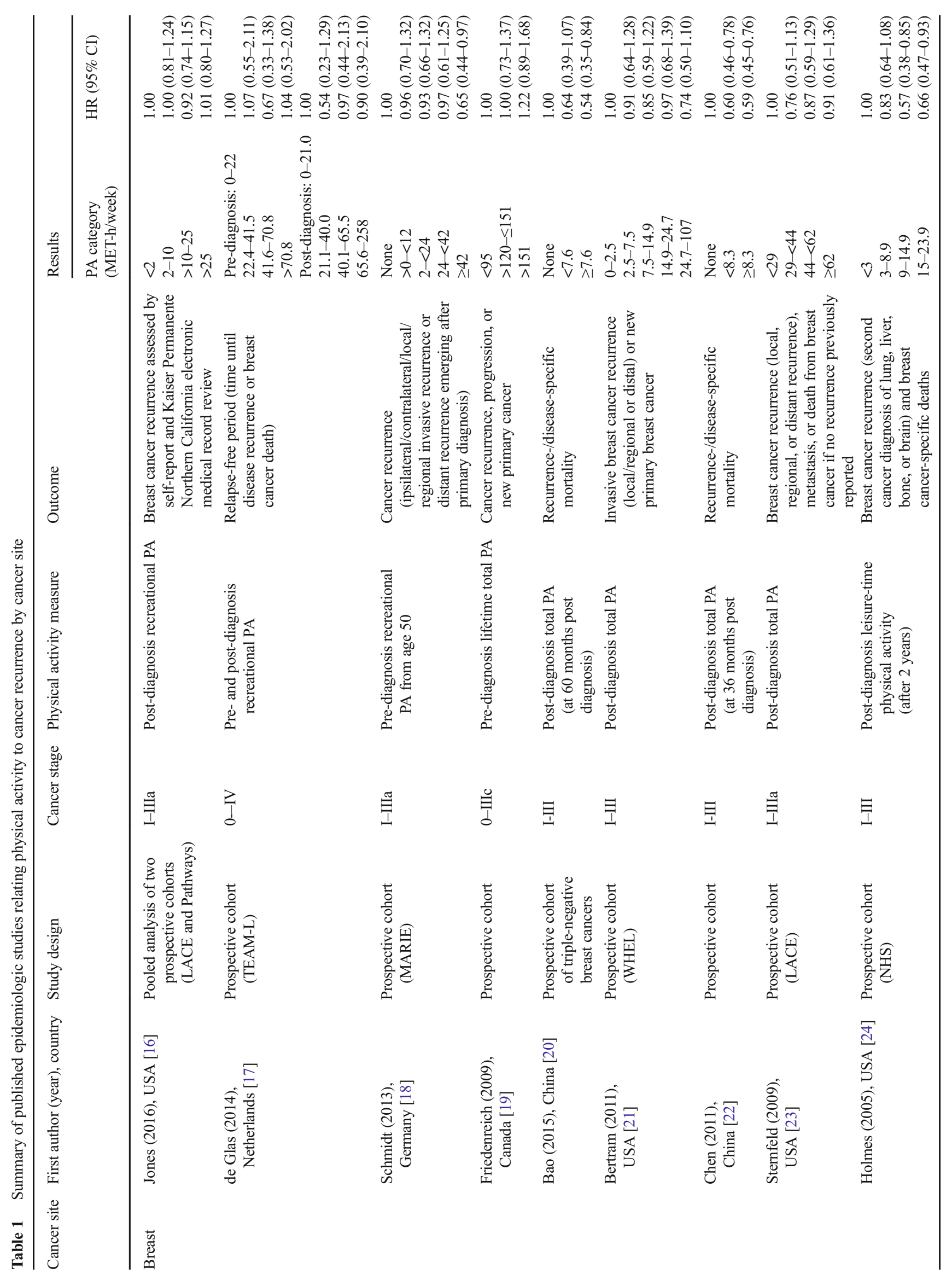




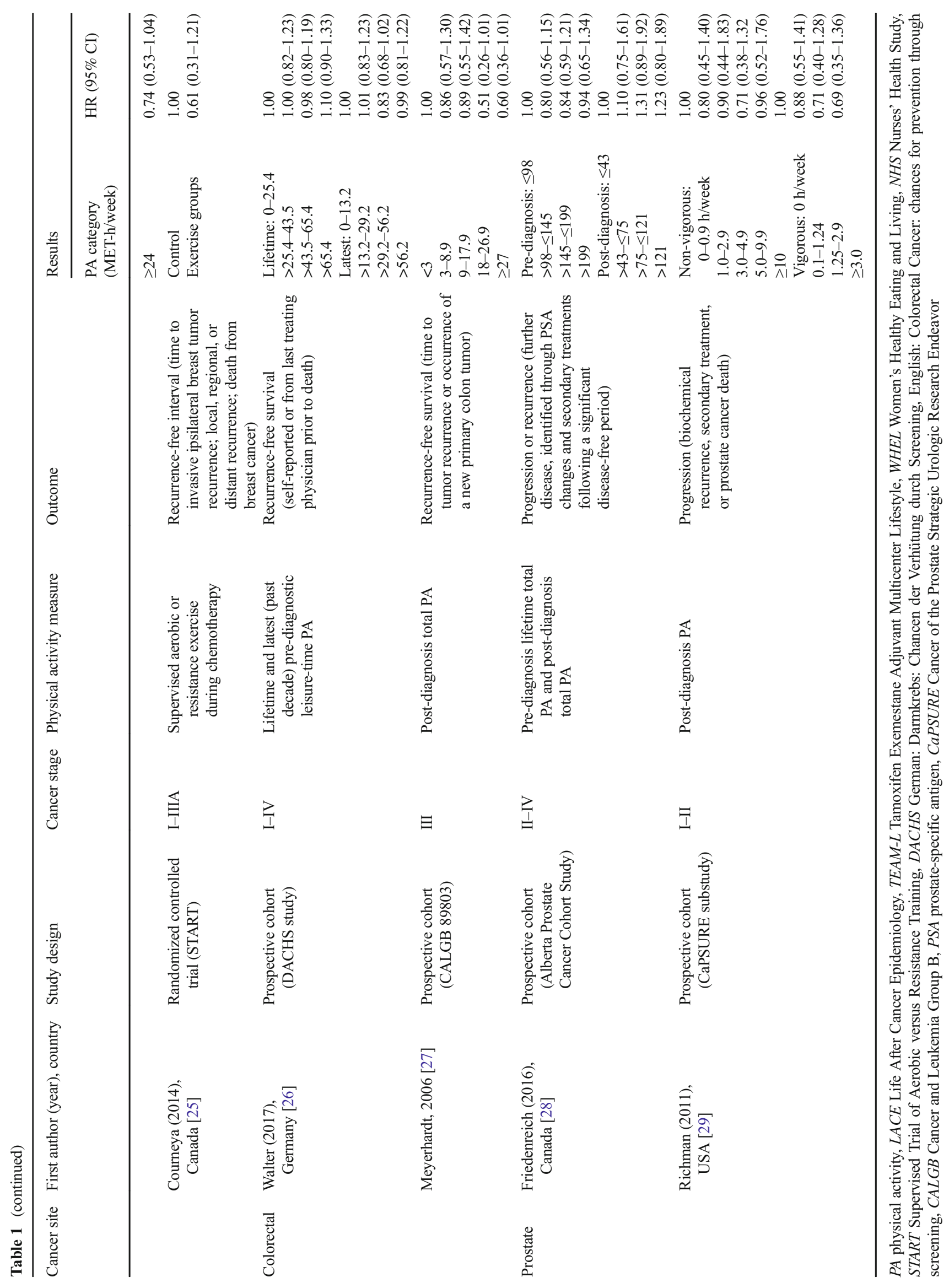


past decade. The interrelated mechanisms most often studied in relation to physical activity and cancer prognosis (Fig. 1) include changes in whole-body and visceral fatness, metabolic dysregulation (e.g., insulin, glucose, insulin-like growth factors (IGF)), adipokines (e.g., leptin, adiponectin), and sex hormones (e.g., estrogen, testosterone); chronic, low-grade inflammation; oxidative stress causing DNA damage and gene mutations (e.g., tumor suppressor genes); and impaired immune surveillance/function [11, 41-43].

Whether physical activity influences these mechanisms independently or through reductions in adipose tissue volume and endocrine activity is difficult to discern for obesity-related cancers (e.g., colorectal, postmenopausal breast, prostate) since some of the same mechanisms are proposed, although some effects are becoming better understood. In postmenopausal women, for example, body fat is the primary source of endogenous estrogens, which fuel cancer progression in estrogen receptor-positive $(\mathrm{ER}+)$ breast cancer. There is now RCT evidence that, while exercise decreases estradiol levels, much greater decreases occur with weight loss [44] and exercise effects are at least partly mediated by fat loss [45].
Similarly, prolonged sedentary behavior (sitting or lying down) is a hypothesized cancer survival risk factor that may act independently of physical inactivity and body fat [46]. Yet, only in the past decade have epidemiologic studies begun to measure sedentary behavior as a distinct exposure.

Exercise intervention trials are increasingly being conducted to demonstrate exercise modes of action in cancer patients. Structured exercise trials (reviewed in $[47,48]$ ), often in breast cancer patients, have shown mixed effects from exercise on circulating biomarkers such as metabolic factors (IGF-1 or its binding protein IGFBP-3, insulin, glucose, C-peptide, leptin), immune and inflammatory factors (natural killer cell cytotoxicity, pro- and anti-inflammatory cytokines), and measures of oxidative stress (8-oxo-dG, F2-isoprostane). More consistent exercise effects were found for circulating $\mathrm{C}$-reactive protein levels (consistently decreased) and in prostate cancer patients, for testosterone- and prostate-specific antigen levels (consistently no change).

A common limitation of these trials is the uncertainty that circulating blood biomarkers reflect downstream biological activity, whereas epigenetic and gene expression studies do

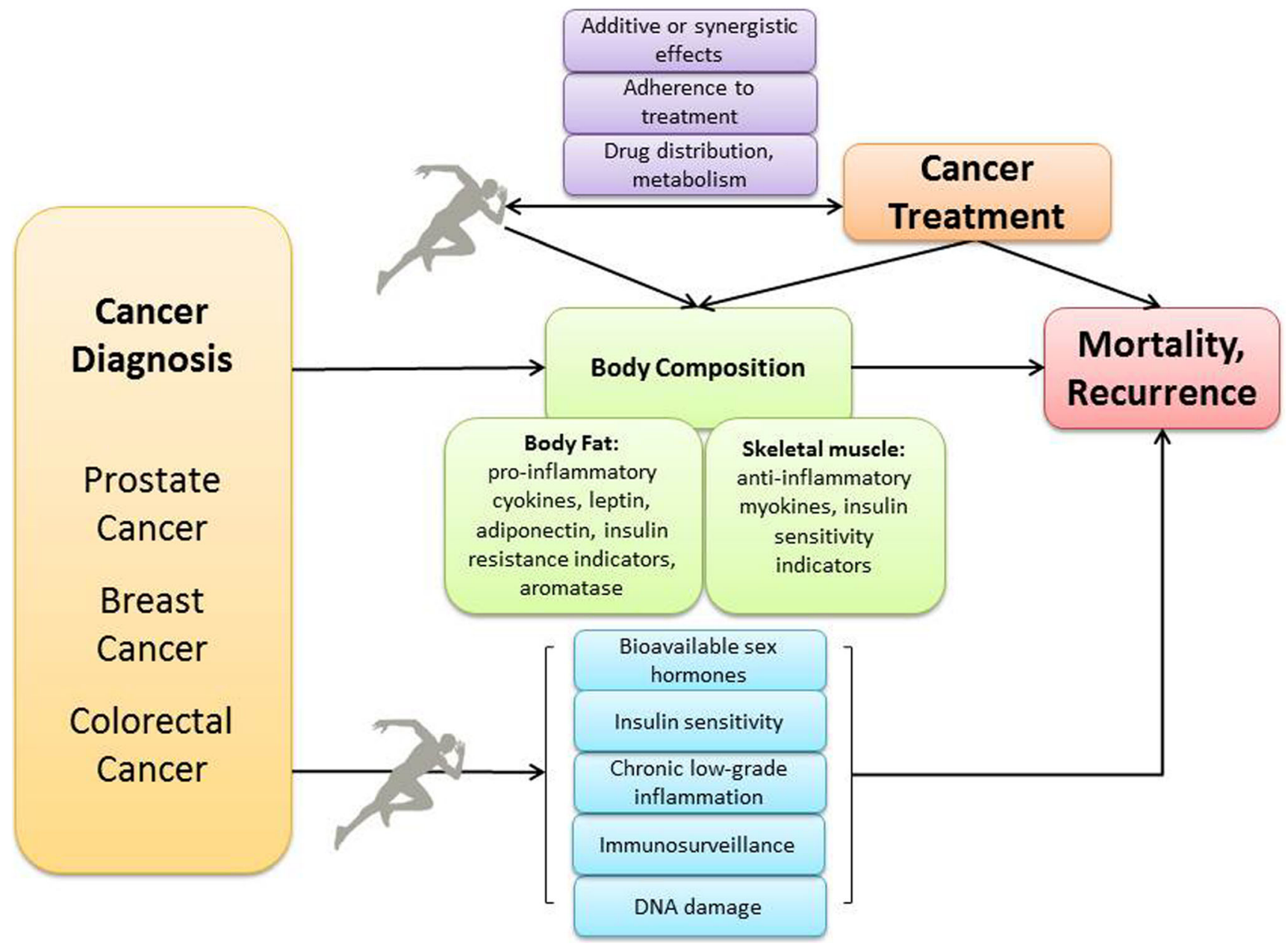

Fig. 1 Commonly proposed mechanisms relating physical activity to cancer recurrence and/or survival. Potential additive or synergistic effects between physical activity and cancer treatment are possible 
not have this limitation. For instance, in colorectal cancer patients, exercise was associated with the $\mathrm{CpG}$ island methylator phenotype (CIMP) and mutations in TP53 and KRAS2 mutations in colon tumor tissue [49] and CIMP-positive tumors are associated with reduced survival [50]. Future exercise trials could potentially measure changes in microRNA, global DNA methylation, and gene-specific methylation, since these outcomes were associated with exercise in previous studies [51, 52]; e.g., higher levels of physical activity have been associated with less frequent CACNA2D3 methylation in gastric adenocarcinoma patients in an observational study [53].

Exercise during first-line and adjuvant chemotherapy might improve treatment efficacy (Fig. 1). Shared mechanisms between exercise and cancer treatment, such as weight loss and decreased sex hormones from exercise combined with the use of aromatase inhibitors, or improved immune function combined with immunotherapy, may generate additive or synergistic improvements. Furthermore, exercise during chemotherapy has been shown to improve adherence to treatment $[25,54]$.

\section{The importance of timing and stage}

A key consideration related to physical activity and cancer recurrence is timing. There is clinical value in understanding whether pre- or post-diagnosis physical activity (or both) prevents cancer recurrence, and whether physical activity prevents early or late recurrences (or both). Early recurrences of a slow-growing cancer could be more strongly influenced by pre-diagnosis activity whereas late recurrences could be more strongly influenced by post-diagnosis activity. Moreover, if risk of recurrence increases with cancer stage at first diagnosis [55], then physical activity mechanistic research should also be stage-specific. This knowledge would help guide mechanistic studies to target early or late carcinogenesis. Ultimately, research to understand the sequence of risk accumulationand physical activity's role at each step in the sequence - will guide prevention messaging and intervention studies, including when to intervene, what benefit to expect, and for what outcome [56].

\section{Colorectal cancer recurrence}

Colorectal cancer serves as a useful example for aligning physical activity timing with risk accumulation because in colorectal cancer the early stages are observable; from field cancerization $[57,58]$ to aberrant crypt foci, to adenomatous polyps, to adenocarcinoma (95\% of cases), to cancer-specific death (Fig. 2). Colorectal cancer may develop over 10 years, resulting from the accumulation of multiple gene mutations - including $A P C$ and KRAS followed by PIK3CA, SMAD4, TP53, and others [59], with only a small proportion of aberrant crypt foci ever progressing to cancer [60]. Recurrences occur in $\sim 40 \%$ of colorectal cases in the USA [13] and happen more quickly than for other cancer sites, with the majority (80-95\%) appearing within 5 years of surgical resection [61]. Given that pre- and post-diagnosis physical activities are associated with better colorectal cancer survival outcomes [62], it is plausible that physical activity influences early- and late-stage mechanisms. Below, we review mechanisms previously proposed for physical activity and colorectal cancer recurrence by stage of carcinogenesis, namely, (1) field cancerization, (2) adenoma recurrence, and (3) adenocarcinoma recurrence.

\section{Field cancerization of the colon}

Field cancerization [63] refers to the concept of an area of otherwise normal epithelial tissue that is 'primed' to undergo transformation (e.g., by methylated DNA [64], altered gene expression [65], etc.), which can either be locally focused or diffuse in an organ such as the colon [58]. This phenomenon may explain colorectal cancer recurrence, with new cancers potentially arising either adjacent to the excised primary tumor or more diffusely where a broader field is observed. There is some evidence from animal studies that exercise can favorably alter DNA methylation patterns. For example, repression of the gene BHMT2, involved in aberrant methylation, was observed in the colons of exercising rats [66]. However, there is inherent complexity with these types of investigations in humans, and therefore, the human evidence to date has been limited with mixed results [46]. In several observational studies, increased physical activity was associated with higher levels of global methylation in peripheral blood $[67,68]$ and exercise was shown to impact levels of global DNA methylation in adipose tissue in an intervention study [69]. However, no intervention trials have examined if exercise induces changes in DNA methylation in colon tissue. Furthermore, no studies have investigated if exercise can reverse the cancerization of a particular field with repeated measures in colon tissues.

\section{Recurrence of adenomas (polyps)}

A number of epidemiologic studies have examined the relation between physical activity [70-72] or sedentary behavior [73-75] and adenoma risk. These studies generally found a benefit from being more active, particularly for adenomas that were large/more advanced. Fewer studies focused on adenoma recurrence [75-78] and, of those, some suggested lower recurrence risk associated with more activity [77] or less sedentary behavior [75] in men.

Physical activity might prevent adenoma recurrence by maintaining energy balance since BMI, waist circumference, and possibly weight change have been associated with higher recurrence risk [79-82]. Correlative studies suggest that adenoma recurrence could be mediated partly by homocysteine 


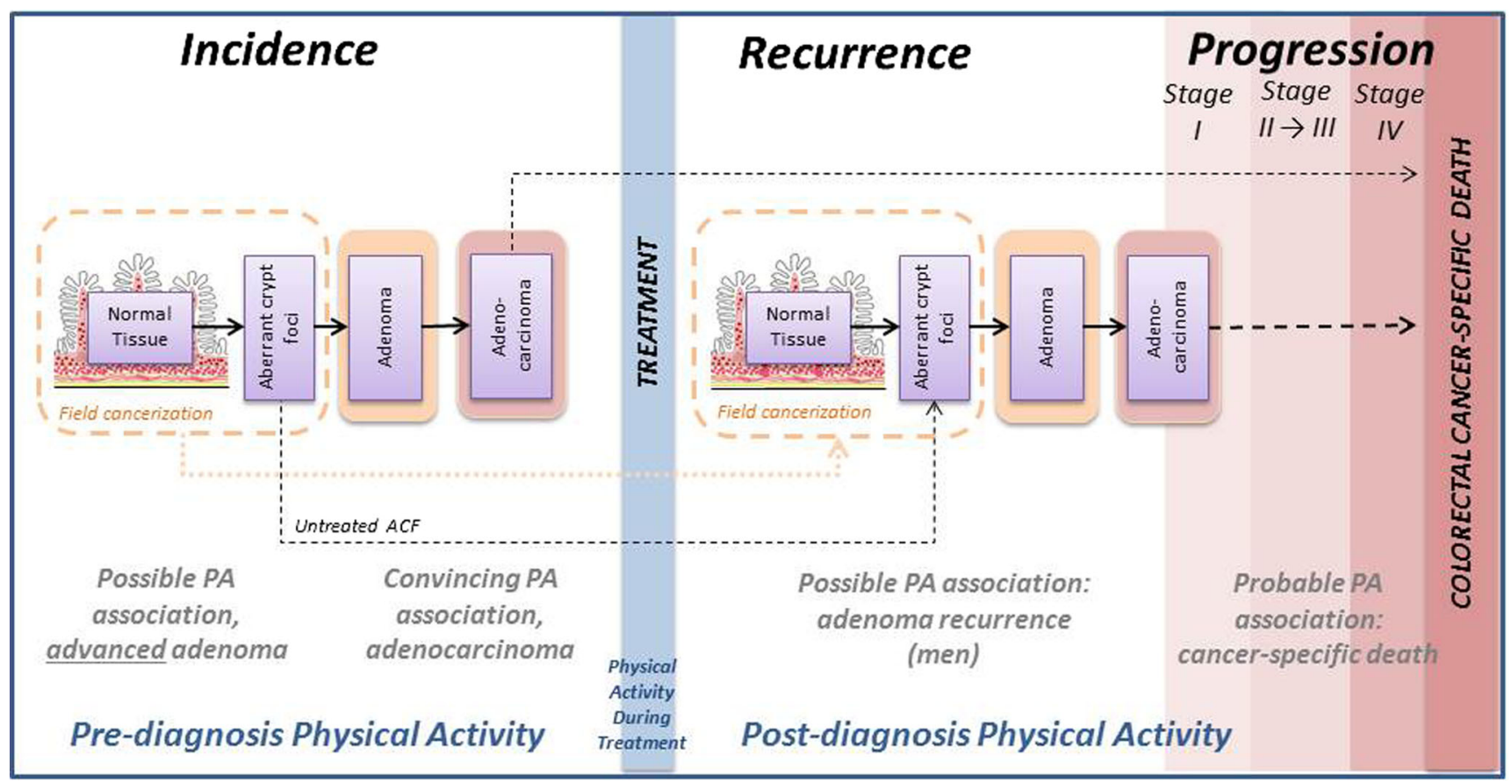

Fig. 2 Colorectal cancer serves as a useful example for studying physical activity mechanisms because risk accumulation is observable. The overall strength and consistency of epidemiologic evidence relating physical activity to colorectal cancer outcomes is strongest for colorectal cancer incidence, somewhat weaker for colorectal cancer mortality (given fewer prospective studies; although results have been relatively consistent,

levels [78], age, blood glucose [83], metabolic syndrome, waist circumference, or waist-to-hip ratio, particularly in men [84]. An inflammatory mechanism (e.g., via COX-2 or STAT3) is plausible since aspirin use [85] and various cytokines [86] are associated with adenoma risk. Adipokines such as leptin and adiponectin, derived from white adipose tissue, are also hypothesized to play direct or indirect opposing roles (leptin unfavorable, adiponectin favorable) mediating cancer cell proliferation, invasion, and survival [87]. However, one epidemiologic study of adenoma recurrence found risk to be lower among individuals with higher leptin levels and there was no association with adiponectin [78].

Few epidemiologic studies have explored insulin resistance biomarkers in relation to adenoma recurrence despite insulin's known mitogenic and anti-apoptotic properties in the colon [88] and exercise responsiveness in other contexts. One epidemiologic study reported an increased risk of adenoma recurrence in adults with higher levels of circulating glucose and insulin [89], although C-peptide, a by-product of insulin secretion, was not associated with recurrence in another study [78].

Other epidemiologic studies investigated IGF-1 and its primary binding protein IGFBP-3, which controls IGF-1 bioavailability, in relation to adenoma recurrence since IGF-1 promotes cell proliferation and inhibits apoptosis [90]. In some prospective studies, inverse associations between baseline IGF-1 levels and future adenoma recurrence were generally showing benefit from both pre- and post-diagnosis physical activity), and weakest for adenoma (polyp) recurrence, due to limited epidemiologic research focused on recurrence outcomes and studies showing significant associations only in men. Solid arrows indicate known pathways. Broken arrows indicate hypothesized pathways. $A C F$, aberrant crypt foci; $P A$, physical activity

reported, perhaps because of better health in the higher-level IGF-1 subgroups [91, 92]. However, the impact of exercise on IGF is most likely to be indirect by altering, for example, IGF1 physiology or through energy balance [93].

\section{Recurrence of adenocarcinoma (cancer)}

The mechanisms most commonly proposed for colorectal cancer recurrence, besides tumor stage, location, and cancer treatment, include $K R A S$ and mismatch repair gene mutations, microsatellite instability status [94], and MCMT promoter methylation [95]. Furthermore, many of the same mechanisms proposed for adenoma recurrence are proposed for cancer recurrence; these mechanisms and others are discussed below.

Diabetic patients and those with increased number of metabolic syndrome conditions are at increased risk of colorectal cancer recurrence (or reduced recurrence/disease-free survival) $[96,97]$, suggesting a role for metabolic dysregulation. There is inconsistent evidence that increased insulin and IGF-1 are associated with worse prognosis in colorectal cancer patients [98-100]. Higher IGFBP-3 levels may be associated with a reduced risk of colorectal cancer-specific death [100]. However, these associations have not been wellstudied for recurrence. Only one study by Lee et al. [48] investigated the effect of a physical activity intervention on the IGF-1 axis in colorectal cancer patients. Results indicated that 
increased physical activity significantly decreased insulin levels and homeostasis model assessment of insulin resistance and increased IGF-1 and IGFBP-3 levels. These results support the IGF-1 axis as a potential mechanism underlying physical activity benefits, with the exception of the increase in IGF-1 levels, which the authors explained by a correlation between IGF-1 and lean mass at baseline.

Tumor-promoting inflammation is an enabling characteristic of cancer [101] that has been implicated in colorectal cancer recurrence [102], yet it is unclear if exercise is protective. In rats, exercise has attenuated chemically induced COX-2 expression and cell proliferation in the colon [103], modeling early stage prevention. Myokines might be involved, which are cytokines and other peptides released from muscle cells that promote anti-inflammatory effects and insulin sensitivity; interleukin-6 is the most commonly studied [42, 104]. Secreted protein acidic and rich in cysteine (SPARC) is a myokine recently studied in relation to early colorectal carcinogenesis that prevented aberrant crypt formation in mice [105]. However, a small trial in humans did not find SPARC levels to be exercise-responsive [106]. A commonly studied pro-inflammatory cancer biomarker is TNF- $\alpha$. Higher TNF- $\alpha$ expression in colon tumor tissue has been associated with positive lymph node stage and colon cancer recurrence [107], and there is some evidence that circulating TNF- $\alpha$ levels can be lowered with exercise in animal models [108] and in colon cancer patients [48] although this effect is not found consistently in cancer patients [47].

Chronic exercise might decrease recurrence risk by lowering systemic oxidative stress, resulting from immune cell overproduction of reactive oxygen species (ROS). The genetic and epigenetic changes induced by ROS may contribute to the initiation and progression of colorectal cancer [109]. Chronic exercise could reduce oxidative stress by inducing an adaptive response since exercise itself induces ROS production in skeletal muscle [110]. Alternatively, exercise may decrease ROS exposure by lowering hydrophobic bile acid concentrations [111] perhaps via decreased serum cholesterol [112]. Recently, a large RCT in overweight/obese postmenopausal women showed a significant decrease in circulating $\mathrm{F}_{2^{-}}$ isoprostane levels after 12 months of exercise, but no change in fluorescent oxidation products or oxidized low-density lipoprotein levels [113].

Multiple epigenetic alterations have been implicated in the development and prognosis [114] of colorectal adenocarcinoma. These include but are not limited to the CIMP phenotype [50] (often identified through the methylation of RUNX3, SOCS1, NEUROG1, CACNA1G, and IGF) [115], global hypomethylation and hypermethylation of tumor suppressor genes (CDKN2A and ESR, APC, KRAS, MGMT) [116], and alterations in microRNA (miRNA) expression [117]. While the impact of these epigenetic alterations on prognosis has been relatively well characterized, given the challenges in adequately measuring exercise in cancer patients in observational studies, the impact of exercise has been mixed [118]. One study examined gene expression in the colons of exercising rats and discovered reduced transcript levels for VEGF (vascularization), ANG-2 (vascularization), and iPL-A2 (signal transduction) [66]. While epigenetic markers such as miRNA panels provide interesting etiologic candidates in observational studies, several limitations to their use should be noted. For the example of miRNA, major limitations include variability in miRNA isolation and extraction [119], as well as the cross-platform variation in results from miRNA quantification [120]. Furthermore, within-platform differences have been observed across commercial offerings, which further limits their broad applicability [121]. As the research advances, additional attention should be given to standardization of sample collection and storage as well as of methods for quantification and analyses (normalization).

\section{Colorectal cancer recurrence: when could exercise be beneficial?}

Our review of physical activity and colorectal cancer mechanisms shows that, to date, the strongest evidence relating physical activity to colorectal cancer recurrence in humans relates to "near-diagnosis" processes (i.e., not initiation, not late-stage), namely, weight control and insulin-related pathways. Inflammatory pathways could mediate adenoma (polyp) recurrence in some subgroups (e.g., men), although clarity is needed to understand whether physical activity, sedentary behavior, or body fatness is driving this mediation.

Perhaps the greatest immediate opportunity for mechanistic research relates to the role of exercise in early, initiating events in colorectal cancer (e.g., preventing field cancerization and aberrant crypt foci). Currently, there is very little evidence in humans that exercise modulates these events. Late-stage carcinogenic pathways are also not well understood, in part because epidemiologic survival studies of physical activity often exclude stage IV cases (Table 1) to avoid possible reverse causation, and trials to understand exercise modes of action have been infrequently conducted in this group. Although tumor-promoting inflammation and avoiding immune destruction are enabling characteristics of cancer [101], there is still very little direct evidence that exercise alters these pathways in the colon. Comparatively more evidence suggests insulin-glucose regulation may be involved in adenocarcinoma recurrence.

\section{Future directions}

Presently, there is limited epidemiologic evidence relating physical activity to cancer recurrence. Rather, benefit is inferred from cancer survival studies which often focus on post- 
diagnosis physical activity in breast, colorectal, and prostate cancer survivors. There may be benefit from considering prediagnosis activity as well as cancer stage at diagnosis and timing of recurrence (early/late) in future epidemiologic studies, to guide mechanistic research. In addition, standardized, cancer-specific definitions of recurrence are needed to build a more consistent body of epidemiologic evidence regarding recurrence. The possibility that physical activity-recurrence associations are partly explained by body fatness and sedentary behavior, or perhaps diet quality [11], must also be carefully considered when interpreting observational studies. Ideally, future observational cohort studies of physical activity and cancer recurrence should be designed to include objective measurements of physical activity, sedentary behavior, body composition, other health-related factors, and biologic mechanisms within the same study population as is being done in the ongoing Alberta Moving Beyond Breast Cancer cohort study [122].

There are some indications about how physical activity might influence cancer recurrence mechanisms, although for some mechanisms (e.g., IGF, oxidative stress, epigenetic mechanisms) there is uncertainty regarding whether or not they are modifiable with exercise while for others (e.g., circulating biomarkers), it is unclear if they are strongly predictive of recurrence. Research from RCTs that demonstrate both exercise responsiveness and clinical relevance is needed. Furthermore, studies that examine the impact of exercise on the reversibility of field cancerization or early carcinogenic events (e.g., in colorectal cancer), with repeated longitudinal sampling from tissues of interest, are needed.

Although our recurrence model focused on colorectal cancer, the same thought process of considering mechanisms separately for precancerous outcomes is useful for studying the role of lifestyle factors in the recurrence of other slowgrowing cancers. This level of mechanistic insight is crucial for informing recommendations about when to exercise and for anticipating additive or synergistic effects with other preventive behaviors or treatments.

Acknowledgments Christine Friedenreich is funded by an Alberta Innovates Health Solutions Health Senior Scholar Award and the Alberta Cancer Foundation Weekend to End Women's Cancers Breast Cancer Chair. Darren Brenner holds a Capacity Development Award in Cancer Prevention from the Canadian Cancer Society Research Institute (\#703917).

Conflicts of interest The authors declare that they have no conflicts of interest.

Open Access This article is distributed under the terms of the Creative Commons Attribution 4.0 International License (http:// creativecommons.org/licenses/by/4.0/), which permits unrestricted use, distribution, and reproduction in any medium, provided you give appropriate credit to the original author(s) and the source, provide a link to the Creative Commons license, and indicate if changes were made.

\section{References}

1. Moore SC, Lee IM, Weiderpass E, Campbell PT, Sampson JN, Kitahara CM, Keadle SK, Arem H, Berrington de Gonzalez A, Hartge P et al (2016) Association of leisure-time physical activity with risk of 26 types of cancer in 1.44 million adults. JAMA Intern Med 176:816-825

2. Liu L, Shi Y, Li T, Qin Q, Yin J, Pang S, Nie S, Wei S (2016) Leisure time physical activity and cancer risk: evaluation of the WHO's recommendation based on 126 high-quality epidemiological studies. Br J Sports Med 50:372-378

3. Li T, Wei S, Shi Y, Pang S, Qin Q, Yin J, Deng Y, Chen Q, Wei S, Nie $S$ et al (2016) The dose-response effect of physical activity on cancer mortality: findings from 71 prospective cohort studies. Br J Sports Med 50:339-345

4. Harris SR (2009) Physical activity and breast cancer mortality. Eur J Oncol Nurs 13:233-234

5. Ibrahim EM, Al-Homaidh A (2011) Physical activity and survival after breast cancer diagnosis: meta-analysis of published studies. Med Oncol 28:753-765

6. Ligibel J (2012) Lifestyle factors in cancer survivorship. J Clin Oncol 30:3697-3704

7. Loprinzi PD, Cardinal BJ, Winters-Stone K, Smit E, Loprinzi CL (2012) Physical activity and the risk of breast cancer recurrence: a literature review. Oncol Nurs Forum 39:269-274

8. Ellsworth RE, Valente AL, Shriver CD, Bittman B, Ellsworth DL (2012) Impact of lifestyle factors on prognosis among breast cancer survivors in the USA. Expert Rev Pharmacoecon Outcomes Res 12:451-464

9. Chlebowski RT (2013) Nutrition and physical activity influence on breast cancer incidence and outcome. Breast 22(Suppl 2):S30 S37

10. Lahart IM, Metsios GS, Nevill AM, Carmichael AR (2015) Physical activity, risk of death and recurrence in breast cancer survivors: a systematic review and meta-analysis of epidemiological studies. Acta Oncol 54:635-654

11. Dieli-Conwright CM, Lee K, Kiwata JL (2016) Reducing the risk of breast cancer recurrence: an evaluation of the effects and mechanisms of diet and exercise. Curr Breast Cancer Rep 8:139-150

12. Simard S, Thewes B, Humphris G, Dixon M, Hayden C, Mireskandari S, Ozakinci G (2013) Fear of cancer recurrence in adult cancer survivors: a systematic review of quantitative studies. J Cancer Surviv 7:300-322

13. Siegel R, DeSantis C, Virgo K, Stein K, Mariotto A, Smith T, Cooper D, Gansler T, Lerro C, Fedewa S et al (2012) Cancer treatment and survivorship statistics, 2012. CA Cancer J Clin 62: 220-241

14. Brewster AM, Hortobagyi GN, Broglio KR, Kau SW, SantaMaria CA, Arun B, Buzdar AU, Booser DJ, Valero V, Bondy M et al (2008) Residual risk of breast cancer recurrence 5 years after adjuvant therapy. J Natl Cancer Inst 100:1179-1183

15. Schmid D, Leitzmann MF (2014) Association between physical activity and mortality among breast cancer and colorectal cancer survivors: a systematic review and meta-analysis. Ann Oncol 25: 1293-1311

16. Jones LW, Kwan ML, Weltzien E, Chandarlapaty S, Sternfeld B, Sweeney C, Bernard PS, Castillo A, Habel LA, Kroenke CH et al (2016) Exercise and prognosis on the basis of clinicopathologic and molecular features in early-stage breast cancer: the LACE and pathways studies. Cancer Res 76:5415-5422

17. de Glas NA, Fontein DB, Bastiaannet E, Pijpe A, De Craen AJ, Liefers GJ, Nortier HJ, de Haes HJ, van de Velde CJ, van Leeuwen FE (2014) Physical activity and survival of postmenopausal, hormone receptor-positive breast cancer patients: results of the 
tamoxifen Exemestane adjuvant multicenter lifestyle study. Cancer 120:2847-2854

18. Schmidt ME, Chang-Claude J, Vrieling A, Seibold P, Heinz J, Obi N, Flesch-Janys D, Steindorf K (2013) Association of prediagnosis physical activity with recurrence and mortality among women with breast cancer. Int J Cancer 133:1431-1440

19. Friedenreich CM, Gregory J, Kopciuk KA, Mackey JR, Courneya KS (2009) Prospective cohort study of lifetime physical activity and breast cancer survival. Int J Cancer 124:1954-1962

20. Bao PP, Zhao GM, Shu XO, Peng P, Cai H, Lu W, Zheng Y (2015) Modifiable lifestyle factors and triple-negative breast cancer survival: a population-based prospective study. Epidemiology 26: 909-916

21. Bertram LA, Stefanick ML, Saquib N, Natarajan L, Patterson RE, Bardwell W, Flatt SW, Newman VA, Rock CL, Thomson CA et al (2011) Physical activity, additional breast cancer events, and mortality among early-stage breast cancer survivors: findings from the WHEL Study. Cancer Causes Control 22:427-435

22. Chen X, Lu W, Zheng W, Gu K, Matthews CE, Chen Z, Zheng Y, Shu XO (2011) Exercise after diagnosis of breast cancer in association with survival. Cancer Prev Res (Phila) 4:1409-1418

23. Sternfeld B, Weltzien E, Quesenberry CP Jr, Castillo AL, Kwan M, Slattery ML, Caan BJ (2009) Physical activity and risk of recurrence and mortality in breast cancer survivors: findings from the LACE study. Cancer Epidemiol Biomark Prev 18:87-95

24. Holmes MD, Chen WY, Feskanich D, Kroenke CH, Colditz GA (2005) Physical activity and survival after breast cancer diagnosis. JAMA 293:2479-2486

25. Courneya KS, Segal RJ, McKenzie DC, Dong H, Gelmon K, Friedenreich CM, Yasui Y, Reid RD, Crawford JJ, Mackey JR (2014) Effects of exercise during adjuvant chemotherapy on breast cancer outcomes. Med Sci Sports Exerc 46:1744-1751

26. Walter V, Jansen L, Knebel P, Chang-Claude J, Hoffmeister M, Brenner H (2017) Physical activity and survival of colorectal cancer patients: population-based study from Germany. Int J Cancer. doi:10.1002/ijc.30619

27. Meyerhardt JA, Heseltine D, Niedzwiecki D, Hollis D, Saltz LB, Mayer RJ, Thomas J, Nelson H, Whittom R, Hantel A et al (2006) Impact of physical activity on cancer recurrence and survival in patients with stage III colon cancer: findings from CALGB 89803. J Clin Oncol 24:3535-3541

28. Friedenreich CM, Wang Q, Neilson HK, Kopciuk KA, McGregor SE, Courneya KS (2016) Physical activity and survival after prostate cancer. Eur Urol 70:576-585

29. Richman EL, Kenfield SA, Stampfer MJ, Paciorek A, Carroll PR, Chan JM (2011) Physical activity after diagnosis and risk of prostate cancer progression: data from the cancer of the prostate strategic urologic research endeavor. Cancer Res 71:3889-3895

30. Warren JL, Yabroff KR (2015) Challenges and opportunities in measuring cancer recurrence in the United States. J Natl Cancer Inst:107. doi:10.1093/jnci/djv134

31. Winkels RM, Heine-Broring RC, van Zutphen M, van HartenGerritsen S, Kok DE, van Duijnhoven FJ, Kampman E (2014) The COLON study: Colorectal cancer: Longitudinal, Observational study on Nutritional and lifestyle factors that may influence colorectal tumour recurrence, survival and quality of life. BMC Cancer 14:374

32. Soares-Miranda L, Abreu S, Silva M, Peixoto A, Ramalho R, da Silva PC, Costa C, Teixeira JP, Goncalves C, Moreira P et al (2017) Cancer Survivor Study (CASUS) on colorectal patients: longitudinal study on physical activity, fitness, nutrition, and its influences on quality of life, disease recurrence, and survival. Rationale and design. Int J Color Dis 32:75-81

33. Taira N, Akiyama I, Ishihara S, Ishibe Y, Kawasaki K, Saito M, Shien T, Nomura T, Hara F, Mizoo T et al (2015) Impact of modifiable lifestyle factors on outcomes after breast cancer diagnosis: the Setouchi Breast Cancer Cohort Study. Jpn J Clin Oncol 45: 600-602

34. Islam T, Bhoo-Pathy $\mathrm{N}$, Su TT, Majid HA, Nahar AM, Ng CG, Dahlui M, Hussain S, Cantwell M, Murray L et al (2015) The Malaysian Breast Cancer Survivorship Cohort (MyBCC): a study protocol. BMJ Open 5:e008643

35. Courneya KS, Booth CM, Gill S, O'Brien P, Vardy J, Friedenreich $\mathrm{CM}, \mathrm{Au} \mathrm{HJ}$, Brundage MD, Tu D, Dhillon H et al (2008) The Colon Health and Life-Long Exercise Change trial: a randomized trial of the National Cancer Institute of Canada Clinical Trials Group. Curr Oncol 15:279-285

36. Rock CL, Byers TE, Colditz GA, Demark-Wahnefried W, Ganz PA, Wolin KY, Elias A, Krontiras H, Liu J, Naughton M et al (2013) Reducing breast cancer recurrence with weight loss, a vanguard trial: the Exercise and Nutrition to Enhance Recovery and Good Health for You (ENERGY) Trial. Contemp Clin Trials 34: 282-295

37. Rack B, Andergassen U, Neugebauer J, Salmen J, Hepp P, Sommer H, Lichtenegger W, Friese K, Beckmann MW, Hauner D et al (2010) The German SUCCESS C study-the first European lifestyle study on breast cancer. Breast Care (Basel) 5: 395-400

38. Arun B, Austin T, Babiera GV, Basen-Engquist K, Carmack CL, Chaoul A, Cohen L, Connelly L, Haddad R, Harrison C et al (2016) A comprehensive lifestyle randomized clinical trial: design and initial patient experience. Integr Cancer Ther. doi:10.1177/ 1534735416679516

39. Augustin LS, Libra M, Crispo A, Grimaldi M, De Laurentiis M, Rinaldo M, D'Aiuto M, Catalano F, Banna G, Ferrau F et al (2017) Low glycemic index diet, exercise and vitamin $\mathrm{D}$ to reduce breast cancer recurrence (DEDiCa): design of a clinical trial. BMC Cancer 17:69

40. Villarini A, Pasanisi P, Traina A, Mano MP, Bonanni B, Panico S, Scipioni C, Galasso R, Paduos A, Simeoni M et al (2012) Lifestyle and breast cancer recurrences: the DIANA-5 trial. Tumori 98:1-18

41. Koelwyn GJ, Wennerberg E, Demaria S, Jones LW (2015) Exercise in regulation of inflammation-immune axis function in cancer initiation and progression. Oncology (Williston Park) 29: 214800

42. Mathur N, Pedersen BK (2008) Exercise as a mean to control lowgrade systemic inflammation. Mediat Inflamm 2008:1-6

43. Champ CE, Francis L, Klement RJ, Dickerman R, Smith RP (2016) Fortifying the treatment of prostate cancer with physical activity. Prostate Cancer 2016:9462975

44. Campbell KL, Foster-Schubert KE, Alfano CM, Wang CC, Wang CY, Duggan CR, Mason C, Imayama I, Kong A, Xiao L et al (2012) Reduced-calorie dietary weight loss, exercise, and sex hormones in postmenopausal women: randomized controlled trial. J Clin Oncol 30:2314-2326

45. Friedenreich CM, Woolcott CG, McTiernan A, Ballard-Barbash R, Brant RF, Stanczyk FZ, Terry T, Boyd NF, Yaffe MJ, Irwin ML et al (2010) Alberta physical activity and breast cancer prevention trial: sex hormone changes in a year-long exercise intervention among postmenopausal women. J Clin Oncol 28:1458-1466

46. Hibler E (2015) Epigenetics and colorectal neoplasia: the evidence for physical activity and sedentary behavior. Curr Colorectal Cancer Rep 11:388-396

47. Betof AS, Dewhirst MW, Jones LW (2013) Effects and potential mechanisms of exercise training on cancer progression: a translational perspective. Brain Behav Immun 30(Suppl):S75-S87

48. Lee DH, Kim JY, Lee MK, Lee C, Min JH, Jeong DH, Lee JW, Chu SH, Meyerhardt JA, Ligibel J et al (2013) Effects of a 12week home-based exercise program on the level of physical activity, insulin, and cytokines in colorectal cancer survivors: a pilot study. Support Care Cancer 21:2537-2545 
49. Slattery ML, Curtin K, Wolff RK, Herrick JS, Caan BJ, Samowitz W (2010) Diet, physical activity, and body size associations with rectal tumor mutations and epigenetic changes. Cancer Causes Control 21:1237-1245

50. Phipps AI, Limburg PJ, Baron JA, Burnett-Hartman AN, Weisenberger DJ, Laird PW, Sinicrope FA, Rosty C, Buchanan DD, Potter JD et al (2015) Association between molecular subtypes of colorectal cancer and patient survival. Gastroenterology 148:77-87.e72

51. Tonevitsky AG, Maltseva DV, Abbasi A, Samatov TR, Sakharov DA, Shkurnikov MU, Lebedev AE, Galatenko VV, Grigoriev AI, Northoff H (2013) Dynamically regulated miRNA-mRNA networks revealed by exercise. BMC Physiol 13:9

52. Voisin S, Eynon N, Yan X, Bishop DJ (2015) Exercise training and DNA methylation in humans. Acta Physiol (Oxf) 213:39-59

53. Yuasa Y, Nagasaki H, Akiyama Y, Hashimoto Y, Takizawa T, Kojima K, Kawano T, Sugihara K, Imai K, Nakachi K (2009) DNA methylation status is inversely correlated with green tea intake and physical activity in gastric cancer patients. Int J Cancer 124:2677-2682

54. Jones LW, Dewhirst MW (2014) Therapeutic properties of aerobic training after a cancer diagnosis: more than a one-trick pony? J Natl Cancer Inst 106:dju042

55. O'Connell MJ, Campbell ME, Goldberg RM, Grothey A, Seitz JF, Benedetti JK, Andre T, Haller DG, Sargent DJ (2008) Survival following recurrence in stage II and III colon cancer: findings from the ACCENT data set. J Clin Oncol 26:2336-2341

56. Wei EK, Wolin KY, Colditz GA (2010) Time course of risk factors in cancer etiology and progression. J Clin Oncol 28:4052-4057

57. Shen L, Kondo Y, Rosner GL, Xiao L, Hernandez NS, Vilaythong J, Houlihan PS, Krouse RS, Prasad AR, Einspahr JG et al (2005) MGMT promoter methylation and field defect in sporadic colorectal cancer. JNCI: J Natl Cancer Inst 97:1330-1338

58. Luo Y, Yu M, Grady WM (2014) Field cancerization in the colon: a role for aberrant DNA methylation? Gastroenterol Rep (Oxf) 2: $16-20$

59. Vogelstein B, Papadopoulos N, Velculescu VE, Zhou S, Diaz LA Jr, Kinzler KW (2013) Cancer genome landscapes. Science 339: $1546-1558$

60. Alrawi SJ, Schiff M, Carroll RE, Dayton M, Gibbs JF, Kulavlat M, Tan D, Berman K, Stoler DL, Anderson GR (2006) Aberrant crypt foci. Anticancer Res 26:107-119

61. Makhoul R, Alva S, Wilkins KB (2015) Surveillance and survivorship after treatment for colon cancer. Clin Colon Rectal Surg 28:262-270

62. Je Y, Jeon JY, Giovannucci EL, Meyerhardt JA (2013) Association between physical activity and mortality in colorectal cancer: a meta-analysis of prospective cohort studies. Int J Cancer 133:1905-1913

63. Slaughter DP, Southwick HW, Smejkal W (1953) Field cancerization in oral stratified squamous epithelium; clinical implications of multicentric origin. Cancer 6:963-968

64. Grady WM (2005) Epigenetic events in the colorectum and in colon cancer. Biochem Soc Trans 33:684-688

65. Jothy S, Flanders TY, Nowacki PM (1996) New developments in the molecular pathology of human colon cancer: relevance to pathogenesis and diagnosis. Adv Anat Pathol 3:343-350

66. Buehlmeyer K, Doering F, Daniel H, Kindermann B, Schulz T, Michna H (2008) Alteration of gene expression in rat colon mucosa after exercise. Ann Anat 190:71-80

67. Luttropp K, Nordfors L, Ekstrom TJ, Lind L (2013) Physical activity is associated with decreased global DNA methylation in Swedish older individuals. Scand J Clin Lab Invest 73:184-185

68. White AJ, Sandler DP, Bolick SC, Xu Z, Taylor JA, DeRoo LA (2013) Recreational and household physical activity at different time points and DNA global methylation. Eur J Cancer 49:2199_ 2206

69. Ronn T, Volkov P, Davegardh C, Dayeh T, Hall E, Olsson AH, Nilsson E, Tornberg A, Dekker Nitert M, Eriksson KF et al (2013) A six months exercise intervention influences the genome-wide DNA methylation pattern in human adipose tissue. PLoS Genet 9: e1003572

70. Wolin KY, Yan Y, Colditz GA (2011) Physical activity and risk of colon adenoma: a meta-analysis. Br J Cancer 104:882-885

71. Song JH, Kim YS, Yang SY, Chung SJ, Park MJ, Lim SH, Yim JY, Kim JS, Jung HC (2013) Physical activity and other lifestyle factors in relation to the prevalence of colorectal adenoma: a colonoscopy-based study in asymptomatic Koreans. Cancer Causes Control 24:1717-1726

72. Sanchez NF, Stierman B, Saab S, Mahajan D, Yeung H, Francois F (2012) Physical activity reduces risk for colon polyps in a multiethnic colorectal cancer screening population. BMC Res Notes 5:312

73. Cao Y, Keum NN, Chan AT, Fuchs CS, Wu K, Giovannucci EL (2015) Television watching and risk of colorectal adenoma. Br J Cancer 112:934-942

74. Cao Y, Rosner BA, Ma J, Tamimi RM, Chan AT, Fuchs CS, Wu K, Giovannucci EL (2015) Assessing individual risk for high-risk colorectal adenoma at first-time screening colonoscopy. Int J Cancer 137:1719-1728

75. Molmenti CL, Hibler EA, Ashbeck EL, Thomson CA, Garcia DO, Roe D, Harris RB, Lance P, Cisneroz M, Martinez ME et al (2014) Sedentary behavior is associated with colorectal adenoma recurrence in men. Cancer Causes Control 25:1387-1395

76. Colbert LH, Lanza E, Ballard-Barbash R, Slattery ML, Tangrea JA, Caan B, Paskett ED, Iber F, Kikendall W, Lance P et al (2002) Adenomatous polyp recurrence and physical activity in the Polyp Prevention Trial (United States). Cancer Causes Control 13:445453

77. Wallace K, Baron JA, Karagas MR, Cole BF, Byers T, Beach MA, Pearson LH, Burke CA, Silverman WB, Sandler RS (2005) The association of physical activity and body mass index with the risk of large bowel polyps. Cancer Epidemiol Biomark Prev 14:20822086

78. Bobe G, Murphy G, Rogers CJ, Hance KW, Albert PS, Laiyemo AO, Sansbury LB, Lanza E, Schatzkin A, Cross AJ (2010) Serum adiponectin, leptin, C-peptide, homocysteine, and colorectal adenoma recurrence in the Polyp Prevention Trial. Cancer Epidemiol Biomark Prev 19:1441-1452

79. Kitahara CM, Berndt SI, de Gonzalez AB, Coleman HG, Schoen RE, Hayes RB, Huang WY (2013) Prospective investigation of body mass index, colorectal adenoma, and colorectal cancer in the prostate, lung, colorectal, and ovarian cancer screening trial. J Clin Oncol 31:2450-2459

80. Jacobs ET, Martinez ME, Alberts DS, Jiang R, Lance P, Lowe KA, Thompson PA (2007) Association between body size and colorectal adenoma recurrence. Clin Gastroenterol Hepatol 5: 982-990

81. Kim TJ, Kim JE, Choi YH, Hong SN, Kim YH, Chang DK, Rhee PL, Kim MJ, Jung SH, Son HJ (2017) Obesity-related parameters and colorectal adenoma development. J Gastroenterol. doi:10. 1007/s00535-017-1319-0

82. Laiyemo AO, Doubeni C, Badurdeen DS, Murphy G, Marcus PM, Schoen RE, Lanza E, Smoot DT, Cross AJ (2012) Obesity, weight change, and risk of adenoma recurrence: a prospective trial. Endoscopy 44:813-818

83. Taniguchi L, Higurashi T, Uchiyama T, Kondo Y, Uchida E, Uchiyama S, Jono F, Hamanaka J, Kuriyama H, Hata Y et al (2014) Metabolic factors accelerate colorectal adenoma recurrence. BMC Gastroenterol 14:187 
84. Kim MC, Jung SW, Kim CS, Chung TH, Yoo CI, Park NH (2012) Metabolic syndrome is associated with increased risk of recurrent colorectal adenomas in Korean men. Int J Obes 36:1007-1011

85. Kim S, Baron JA, Mott LA, Burke CA, Church TR, McKeownEyssen GE, Cole BF, Haile RW, Sandler RS (2006) Aspirin may be more effective in preventing colorectal adenomas in patients with higher BMI (United States). Cancer Causes Control 17: 1299-1304

86. Comstock SS, Xu D, Hortos K, Kovan B, McCaskey S, Pathak DR, Fenton JI (2016) Association of serum cytokines with colorectal polyp number and type in adult males. Eur J Cancer Prev 25: 173-181

87. Gucalp A, Iyengar NM, Hudis CA, Dannenberg AJ (2016) Targeting obesity-related adipose tissue dysfunction to prevent cancer development and progression. Semin Oncol 43:154-160

88. Sax AT, Jenkins DG, Devin JL, Hughes GI, Bolam KA, Skinner TL (2014) The insulin-like growth factor axis: a biological mechanism linking physical activity to colorectal cancer survival. Cancer Epidemiol 38:455-459

89. Flood A, Mai V, Pfeiffer R, Kahle L, Remaley AT, Lanza E, Schatzkin A (2007) Elevated serum concentrations of insulin and glucose increase risk of recurrent colorectal adenomas. Gastroenterology 133:1423-1429

90. Durai R, Yang W, Gupta S, Seifalian AM, Winslet MC (2005) The role of the insulin-like growth factor system in colorectal cancer: review of current knowledge. Int J Color Dis 20:203-220

91. Flood A, Rastogi T, Wirfalt E, Mitrou PN, Reedy J, Subar AF, Kipnis V, Mouw T, Hollenbeck AR, Leitzmann M et al (2008) Dietary patterns as identified by factor analysis and colorectal cancer among middle-aged Americans. Am J Clin Nutr 88:176184

92. Jacobs ET, Martinez ME, Alberts DS, Ashbeck EL, Gapstur SM, Lance P, Thompson PA (2008) Plasma insulin-like growth factor I is inversely associated with colorectal adenoma recurrence: a novel hypothesis. Cancer Epidemiol Biomark Prev 17:300-305

93. Pollak M (2008) Insulin and insulin-like growth factor signalling in neoplasia. Nat Rev Cancer 8:915-928

94. Wilhelmsen M, Kring T, Jorgensen LN, Madsen MR, Jess P, Bulut O, Nielsen KT, Andersen CL, Nielsen HJ (2014) Determinants of recurrence after intended curative resection for colorectal cancer. Scand J Gastroenterol 49:1399-1408

95. Li Y, Lyu Z, Zhao L, Cheng H, Zhu D, Gao Y, Shang X, Shi H (2015) Prognostic value of MGMT methylation in colorectal cancer: a meta-analysis and literature review. Tumour Biol 36:15951601

96. Meyerhardt JA, Catalano PJ, Haller DG, Mayer RJ, Macdonald JS, Benson AB 3rd, Fuchs CS (2003) Impact of diabetes mellitus on outcomes in patients with colon cancer. J Clin Oncol 21:433440

97. Jeon JY, Jeong DH, Park MG, Lee JW, Chu SH, Park JH, Lee MK, Sato K, Ligibel JA, Meyerhardt JA et al (2013) Impact of diabetes on oncologic outcome of colorectal cancer patients: colon vs. rectal cancer. PLoS One 8:e55196

98. Siegel EM, Ulrich CM, Poole EM, Holmes RS, Jacobsen PB, Shibata D (2010) The effects of obesity and obesity-related conditions on colorectal cancer prognosis. Cancer Control 17:52-57

99. Wolpin BM, Meyerhardt JA, Chan AT, Ng K, Chan JA, Wu K, Pollak MN, Giovannucci EL, Fuchs CS (2009) Insulin, the insulin-like growth factor axis, and mortality in patients with nonmetastatic colorectal cancer. J Clin Oncol 27:176-185

100. Haydon AM, Macinnis RJ, English DR, Morris H, Giles GG (2006) Physical activity, insulin-like growth factor 1, insulin-like growth factor binding protein 3 , and survival from colorectal cancer. Gut 55:689-694

101. Hanahan D, Weinberg RA (2011) Hallmarks of cancer: the next generation. Cell 144:646-674
102. Alonso S, Pascual M, Salvans S, Mayol X, Mojal S, Gil MJ, Grande L, Pera M (2015) Postoperative intra-abdominal infection and colorectal cancer recurrence: a prospective matched cohort study of inflammatory and angiogenic responses as mechanisms involved in this association. Eur J Surg Oncol 41:208-214

103. Demarzo MM, Martins LV, Fernandes CR, Herrero FA, Perez SE, Turatti A, Garcia SB (2008) Exercise reduces inflammation and cell proliferation in rat colon carcinogenesis. Med Sci Sports Exerc 40:618-621

104. Pedersen BK (2011) Exercise-induced myokines and their role in chronic diseases. Brain Behav Immun 25:811-816

105. Aoi W, Naito Y, Takagi T, Tanimura Y, Takanami Y, Kawai Y, Sakuma K, Hang LP, Mizushima K, Hirai Y et al (2013) A novel myokine, secreted protein acidic and rich in cysteine (SPARC), suppresses colon tumorigenesis via regular exercise. Gut 62:882889

106. Songsorn P, Ruffino J, Vollaard NB (2017) No effect of acute and chronic supramaximal exercise on circulating levels of the myokine SPARC. Eur J Sport Sci 17:447-452

107. Grimm M, Lazariotou M, Kircher S, Hofelmayr A, Germer CT, von Rahden BH, Waaga-Gasser AM, Gasser M (2011) Tumor necrosis factor-alpha is associated with positive lymph node status in patients with recurrence of colorectal cancer-indications for anti-TNF-alpha agents in cancer treatment. Cell Oncol (Dordr) 34:315-326

108. Aoi W, Naito Y, Takagi T, Kokura S, Mizushima K, Takanami Y, Kawai Y, Tanimura Y, Hung LP, Koyama R et al (2010) Regular exercise reduces colon tumorigenesis associated with suppression of iNOS. Biochem Biophys Res Commun 399:14-19

109. Ziech D, Franco R, Pappa A, Panayiotidis MI (2011) Reactive oxygen species (ROS) - induced genetic and epigenetic alterations in human carcinogenesis. Mutat Res 711:167-173

110. Radak Z, Chung HY, Goto S (2008) Systemic adaptation to oxidative challenge induced by regular exercise. Free Radic Biol Med 44:153-159

111. Barrasa JI, Olmo N, Lizarbe MA, Turnay J (2013) Bile acids in the colon, from healthy to cytotoxic molecules. Toxicol in Vitro 27: 964-977

112. Wertheim BC, Martinez ME, Ashbeck EL, Roe DJ, Jacobs ET, Alberts DS, Thompson PA (2009) Physical activity as a determinant of fecal bile acid levels. Cancer Epidemiol Biomark Prev 18: $1591-1598$

113. Duggan C, Tapsoba JD, Wang CY, Campbell KL, Foster-Schubert K, Gross MD, McTiernan A (2016) Dietary weight loss, exercise, and oxidative stress in postmenopausal women: a randomized controlled trial. Cancer Prev Res (Phila) 9:835-843

114. Morikawa T, Kuchiba A, Qian ZR, Mino-Kenudson M, Hornick JL, Yamauchi M, Imamura Y, Liao X, Nishihara R, Meyerhardt JA et al (2012) Prognostic significance and molecular associations of tumor growth pattern in colorectal cancer. Ann Surg Oncol 19: 1944-1953

115. Jia M, Gao X, Zhang Y, Hoffmeister M, Brenner H (2016) Different definitions of $\mathrm{CpG}$ island methylator phenotype and outcomes of colorectal cancer: a systematic review. Clin Epigenetics 8:25

116. Toyota M, Ahuja N, Ohe-Toyota M, Herman JG, Baylin SB, Issa JP (1999) CpG island methylator phenotype in colorectal cancer. Proc Natl Acad Sci U S A 96:8681-8686

117. Slattery ML, Herrick JS, Pellatt DF, Stevens JR, Mullany LE, Wolff E, Hoffman MD, Samowitz WS, Wolff RK (2016) MicroRNA profiles in colorectal carcinomas, adenomas and normal colonic mucosa: variations in miRNA expression and disease progression. Carcinogenesis 37:245-261

118. Slattery ML, Herrick JS, Mullany LE, Stevens JR, Wolff RK (2017) Diet and lifestyle factors associated with miRNA expression in colorectal tissue. Pharmgenomics Pers Med 10:1-16 
119. Pritchard CC, Cheng HH, Tewari M (2012) MicroRNA profiling: approaches and considerations. Nat Rev Genet 13:358-369

120. Koshiol J, Wang E, Zhao Y, Marincola F, Landi MT (2010) Strengths and limitations of laboratory procedures for microRNA detection. Cancer Epidemiol Biomark Prev : Publ Am Assoc Cancer Res Cosponsored Am Soc Prev Oncol 19: 907-911
121. Chugh P, Dittmer DP (2012) Potential pitfalls in microRNA profiling. Wiley Interdiscip Rev RNA 3:601-616

122. Courneya KS, Vallance JK, Culos-Reed SN, McNeely ML, Bell GJ, Mackey JR, Yasui Y, Yuan Y, Matthews CE, Lau DC et al (2012) The Alberta Moving Beyond Breast Cancer (AMBER) cohort study: a prospective study of physical activity and healthrelated fitness in breast cancer survivors. BMC Cancer 12:525 